\title{
Lying behavior as an indicator of lameness in dairy cows
}

\author{
K. Ito, ${ }^{*}$ M. A. G. von Keyserlingk, ${ }^{*}$ S. J. LeBlanc, $†$ and D. M. Weary*1 \\ *Animal Welfare Program, Faculty of Land and Food Systems, University of British Columbia, Vancouver, BC, Canada V6T $1 Z 4$ \\ †Department of Population Medicine, Ontario Veterinary College, University of Guelph, Guelph, ON, Canada N1G 2W1
}

\section{ABSTRACT}

Lameness is widely recognized as one of the most serious welfare and production concerns in the dairy industry. Our objectives were to evaluate the associations between lying behavior and lameness, and to determine whether lying behavior can be used as a diagnostic tool for lameness. Electronic data loggers recorded lying behavior of 1,319 cows from 28 farms at 1-min intervals for $5 \mathrm{~d}$. These cows were gait scored according to a 5-point Numerical Rating System (NRS), and categorized as $\mathrm{NRS} \leq 2$, NRS $=3$, or $\mathrm{NRS}=4$; no cow was scored as NRS $=5$. Lameness was dichotomized twice: LAME $(\mathrm{NRS} \geq 3)$ and SEVLAME $(\mathrm{NRS}=4)$. Data were divided into 2 groups: 11 farms using deep-bedded stalls (DB) and 17 farms using mattress stalls (MAT). Differences in the daily lying time $(\mathrm{h} / \mathrm{d})$, frequency of lying bouts (n/d), duration of lying bouts (min/bout), and the standard deviation of bout duration ( $\mathrm{min} /$ bout) between LAME or SEVLAME cows and those that were not were tested using mixed models. Receiver operating characteristic curves were constructed to identify behavioral thresholds to distinguish SEVLAME cows from the rest. Odds ratios for SEVLAME were estimated using logistic regression. Overall, $28.5 \%$ of cows were LAME including $7.3 \%$ that were SEVLAME. The prevalence of SEVLAME was higher on MAT farms than on DB farms $(9.3 \pm 1.3$ vs. $4.4 \pm 1.2 \%$, respectively). SEVLAME cows on DB farms spent 12.8 [confidence interval (CI): 12.0 to 13.7] h/d lying down compared with 11.2 (CI: 10.7 to 11.8) h/d for cows that were not SEVLAME. These cows had longer duration of lying bouts [95.3 (CI: 84.6 to 107.3) vs. 80.3 (CI: 74.9 to 86.1$) \mathrm{min} /$ bout] and greater SD of bout duration [44.4 (CI: 41.1 to 48.0 ) vs. 50.7 (CI: 44.1 to 58.3 ) $\mathrm{min} /$ bout]. There were no behavioral differences among lameness categories on MAT farms. Within DB farms, cows with lying times $>14.5 \mathrm{~h} / \mathrm{d}$ had 16.2 (5.8 to 45.2) times higher odds of being SEVLAME. Cows with average lying bouts $>90 \mathrm{~min} /$ bout were at 3.0 (1.2 to 7.4 )

Received November 26, 2009.

Accepted April 6, 2010.

${ }^{1}$ Corresponding author: danweary@interchange.ubc.ca times higher odds of being SEVLAME, and cows with average SD of bout duration $>55 \mathrm{~min} /$ bout were at 4.1 (1.7 to 9.9) times higher odds of being SEVLAME. These results show that high lying times, long lying bouts, and variability in the duration of lying bouts were associated with lameness, and that stall surface influenced the behavioral responses of lame cows.

Key words: dairy cow, lying behavior, lameness, gait score

\section{INTRODUCTION}

Lameness is widely recognized as a serious animal welfare and production issue in the dairy industry. Recent studies estimated that 20 to $30 \%$ of lactating dairy cows in North America are clinically lame (Cook, 2003; Espejo et al., 2006), with the highest rates observed in herds housed in free-stalls (Cook, 2003; Haskell et al., 2006; Cook and Nordlund, 2009). Cramer et al. (2008) found that $47 \%$ of cows in free-stall herds had lesions on at least 1 foot, and Bicalho et al. (2007a) found that $13 \%$ of cows in a free-stall herd had a painful lesion (i.e., reaction to digital pressure applied to the lesion). Another study estimated lameness at $48 \%$, ranging from 0 to $81 \%$ among 33 free-stall herds in Germany (Dippel et al., 2009). Lameness compromises the welfare of the affected animals (Whay et al., 2003) and can result in reduced milk yield (Warnick et al., 2001; Green et al., 2002; Bicalho et al., 2008), reduced fertility, and increased risk of premature culling (Garbarino et al., 2004; Bicalho et al., 2007b).

Herd-level risk factors for lameness within freestallhoused cows include stall features (Philipot et al., 1994; Espejo and Endres, 2007), lying surface (Cook, 2003; Espejo et al., 2006), overcrowding (Leonard et al., 1996), increased time spent away from the pen for milking (Espejo and Endres, 2007), and the use of automatic alley scrapers (Barker et al., 2007). Dippel et al. (2009) found that reduced lying comfort, measured by the frequency of abnormal lying down and rising behaviors (i.e., interrupted movements, lying down or standing up taking longer than $20 \mathrm{~s}$, lying down with hindquarters first, or rising with forequarters first), was a risk factor for lameness. Increased exposure to hard flooring surfaces between periods of rest combined 
with reduced rest because of an uncomfortable lying environment collectively contributes to lameness (Cook and Nordlund, 2009).

Within a herd, some individuals are more susceptible than others to lameness. Older cows are generally at higher risk (Espejo et al., 2006; Bicalho et al., 2007b; Dippel et al., 2009), and incidence of lameness peaks 3 to 4 mo into lactation (Green et al., 2002). Thinner digital cushion (Bicalho et al., 2009), higher milk production at the beginning of lactation (Green et al., 2002; Bicalho et al., 2008), and low BCS $(<3.0)$ before and at calving (Hoedemaker et al., 2009) were identified as cow-level risk factors for lameness. Galindo et al. (2000) found that cows that became lame spent more time standing with only 2 front feet in the stall compared with cows that did not become lame $(6.2 \%$ vs. $5.6 \%$ of the day, respectively). Galindo and Broom (2000) found that the incidence of lameness was related to standing behavior such that the number of new cases of lameness was higher among cows that spent $>45 \%$ of the day standing.

Lameness may be affected by behavior, but it can also modify the behavior of affected cows (Cook and Nordlund, 2009). In general, lame cows spent more time lying down (Singh et al., 1993; Walker et al., 2008; Chapinal et al., 2009) and less time feeding (González et al., 2008), performed fewer aggressive interactions (Galindo and Broom, 2002), and were less active (O'Callaghan et al., 2003) compared with nonlame cows. Juarez et al. (2003) compared the lying behavior of cows with varying degrees of lameness and found that the proportion of cows lying down within each category increased with the degree of lameness. Cook et al. $(2004,2008)$ found that the type of lying surface affected the behavioral changes due to lameness; lame cows spent more time standing in stalls than nonlame cows, but this difference was greater with mattress stalls compared with sand stalls. These findings show that the resting environment plays an important role in the extent to which behavior is modified by lameness.

Lameness prevalence is often underestimated by producers (Whay et al., 2003; Espejo et al., 2006). Behavioral assessment, such as visual observations of cow gait, is the first line of lameness detection before hoof lesions can be identified during trimming (Bicalho et al., 2007a; Chapinal et al., 2009). Gait scoring is commonly used to detect lameness (Cook, 2003; Espejo et al., 2006; Flower and Weary, 2006), but this method requires some training and time to perform. Automated technology for measuring lying behavior is now available (Ito et al., 2009); inexpensive electronic data loggers can provide precise estimates of lying behavior for individual cows. Our first objective was to evaluate the association between lying behavior and lameness; we predicted that lame cows would show lying behavior different from that of nonlame cows. Our second objective was to determine whether measures of lying behavior could be used as a diagnostic tool for lameness.

\section{MATERIALS AND METHODS}

\section{Farm Selection and Description}

This study was conducted on 28 commercial dairy farms in the Fraser Valley of British Columbia, Canada, between November 2007 and June 2008. As part of a larger study (Ito et al., 2009), 43 farms were recruited from the region. Three local feed suppliers were asked to randomly select 15 of their clients that met the following criteria: free-stall housing, TMR or partially mixed ration with supplemental grain, and milking $>70$ cows. Forty farms were recruited; 3 additional farms that met the same criteria were recruited directly by the research team. Out of these farms, the 11 that used deep-bedded stalls (6 using sand and 5 using sawdust as bedding) and the 17 farms using mattress stalls (geotextile mattress with minimal bedding) were included in the analysis; 14 farms using other types of stall base (concrete, tires, rubber mat, wood, mixed types), and 1 farm using deep-bedded stalls but lacking production records were excluded. For the 28 farms included, herd size was $177 \pm 85$ ( $\pm \mathrm{SD}$, ranging from 83 to 511$)$ milking cows, producing 10,434 \pm 799 (ranging from 8,991 to 12,080$) \mathrm{kg}$ per cow annually. The farms milked twice $(\mathrm{n}=24)$ or 3 times $(\mathrm{n}=4)$ daily, and fed once $(\mathrm{n}=$ $22)$ or twice $(n=6)$ daily. All farms used free-stalls, but varied in several housing measures including barn layout (i.e., number of rows), stall type, and feed bunk structure (i.e., post-and-rail vs. headlocks).

\section{Data Collection}

Each farm was visited twice, with $5 \mathrm{~d}$ between visits. Because heat stress may affect lying time (Cook et al., 2007), the data collection period was limited to days when the maximum temperature was $<25^{\circ} \mathrm{C}$. The average maximum temperature across study days was 9.4 $\pm 5.3^{\circ} \mathrm{C}$ (ranging from -1.0 to $24.5^{\circ} \mathrm{C}$ ). Upon arrival at each farm, the producer was asked to identify 1 pen that housed the high-producing cows; this pen was used for data collection. Six farms housed all lactating cows in a single group, and others separated high-producing from low-producing cows, or multiparous from primiparous cows. The selected group size was $99 \pm 34$ (mean \pm SD, ranging from 47 to 187) cows, and the stall stocking rate was $104 \pm 15$ (ranging from 78 to 157 )\%.

During the afternoon milking on the first visit, up to 50 (47 \pm 3 , ranging from 37 to 50 ) cows were system- 
Table 1. Parity and DIM (mean $\pm \mathrm{SD}$ ) of cows with Numerical Rating Score (NRS) $\leq 2, \mathrm{NRS}=3$, and NRS $=4$ on 11 farms using deep-bedded stalls and 17 farms using mattress stalls

\begin{tabular}{lccc}
\hline Variable & NRS $\leq 2$ & NRS $=3$ & NRS $=4$ \\
\hline Deep-bedded & & & \\
Number of cows (\%) & $397(75.5)$ & $106(20.2)$ & $23(4.4)$ \\
Parity & $2.5 \pm 1.4$ & $3.8 \pm 1.8$ & $3.6 \pm 1.6$ \\
DIM & $146 \pm 95$ & $158 \pm 109$ & $140 \pm 98$ \\
Mattress & & & \\
Number of cows (\%) & $546(68.9)$ & $174(21.9)$ & $73(9.2)$ \\
Parity & $2.3 \pm 1.2$ & $3.0 \pm 1.4$ & $3.6 \pm 1.7$ \\
DIM & $145 \pm 91$ & $159 \pm 87$ & $157 \pm 105$ \\
\hline
\end{tabular}

atically selected as focal cows based on the order they entered the milking parlor; for example, if the group had 100 cows, every second cow that came into the parlor was selected. The sample size was decided based on the availability of the recording devices; however, retrospective analysis established that 30 cows per farm provided a reasonable sample for encompassing variation in lying behavior (Ito et al., 2009). The final sample included 1,319 cows, at 2.6 \pm 1.4 (ranging from 1 to 12 ) lactations and $150 \pm 94$ (ranging from 11 to 581) DIM. Lying behavior of the focal cows was recorded using electronic data loggers (HOBO Pendant G Acceleration Data Loggers, Onset Computer Corp., Pocasset, MA) at 1-min intervals for $5 \mathrm{~d}$ (Ito et al., 2009). Durations of individual lying bouts were computed using Excel macros (Microsoft Corp., Redmond, WA) for the 5-d period, from which daily lying time $(\mathrm{h} / \mathrm{d})$, frequency of lying bouts $(\mathrm{n} / \mathrm{d})$, average duration of lying bouts (min/bout), and the SD of lying bout duration ( $\mathrm{min} /$ bout) were calculated for each cow.

Following the morning milking on the second visit, focal cows had their gait scored as they exited the parlor using a 5-point Numerical Rating System (NRS), where $1=$ sound and $5=$ severely lame (Flower and Weary, 2006). A single trained observer performed all scoring. The observer was trained to score the gait using recorded videos of cows walking in a straight line on a concrete alley (Chapinal et al., 2009); these same video passages were referenced every 2 mo in an effort to minimize changes in the observer's subjective assessment of gait as the study progressed. Before the study, the observer scored 132 cows simultaneously with another experienced observer and achieved high inter-observer agreement (Kappa statistic $=0.94)$.

\section{Lameness Definition}

The NRS uses 6 behavioral criteria (Flower and Weary, 2006), but was simplified for this study by focusing on 3 attributes: asymmetric gait, head bob, and reluctance to bear weight. These attributes were correlated with each other as well as with the overall
NRS score based on the 6 attributes (Chapinal et al., 2009). Cows were categorized as NRS $\leq 2, \mathrm{NRS}=3$, or $\mathrm{NRS}=4$; no cow was scored as NRS $=5$. For statistical analysis, lameness was dichotomized twice to create 2 new variables. The first was LAME, which was considered 1 when NRS $\geq 3$ and 0 when NRS $<3$. The second was SEVLAME, which was considered 1 when NRS = 4 and 0 when NRS $<4$.

\section{Data Analyses}

Data were analyzed using cow as the observational unit. Descriptive summaries were obtained using the SUMMARY and FREQ procedures of SAS (SAS Institute, 2004). Data from farms using deep-bedded stalls (DB; $\mathrm{n}=11$ farms and 526 cows) and farms using mattresses (MAT; $\mathrm{n}=17$ farms and 793 cows) were analyzed separately because there is evidence that stall surface affects the behavior of lame cows (Cook et al., 2004, 2008); preliminary analysis of the current data showed an interaction $(P<0.02)$ between stall surface and NRS. Table 1 provides the descriptive summary of the cows used in analyses.

The differences in herd-level lameness prevalence and lying behaviors between the 2 stall surface categories, stratified by NRS, were tested using the TTEST procedure (SAS Institute, 2004). Normality of data was tested using the UNIVARIATE procedure, and heterogeneity of variance, where necessary, was accounted for by using the Satterthwaite method for computing the standard errors. All other statistical analyses were performed using the GLIMMIX procedure (SAS Institute, 2008). Within each stall surface category, mixed linear regression models were created to test the differences in lying behavior between LAME or SEVLAME cows (1) and cows that were not (0), controlling for the random effect of farm. Compliance with the assumptions of normality and homogeneity of variances were checked visually through residual plots created by the UNIVARIATE and GPLOT procedures (SAS Institute Inc., 2004). Natural logarithm transformation was applied to bout frequency $(\mathrm{n} / \mathrm{d})$, bout duration ( $\mathrm{min} /$ bout), and 


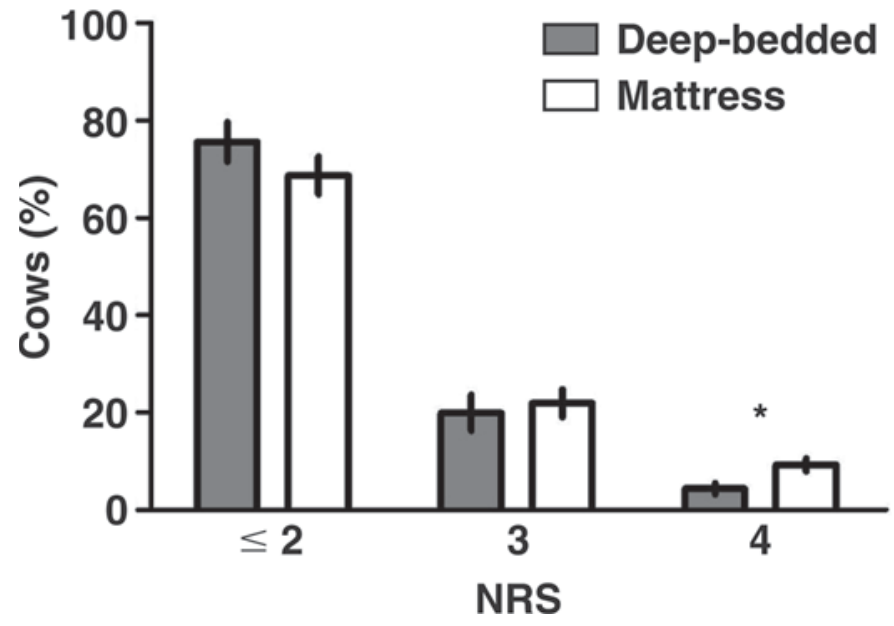

Figure 1. Percentages of cows with Numerical Rating Score (NRS) $<2, \mathrm{NRS}=3$, and NRS $=4$ on 11 farms using deep-bedded stalls and 17 farms using mattress stalls. *Significant difference at $P<0.05$.

the SD of bout duration (min/bout) to normalize these distributions. Extreme outliers (3 times the interquartile range outside of the interquartile limits: $\mathrm{n}=1$ for bout frequency; $\mathrm{n}=5$ for bout duration; $\mathrm{n}=2$ for $\mathrm{SD}$ of bout duration) were removed from analyses. Parity and DIM were forced into all models because they influence lying behavior (Endres and Barberg, 2007) and risk of lameness (Warnick et al., 2001; Espejo et al., 2006; Bicalho et al., 2007b). Parity was classified as 1, 2, 3, and $\geq 4$, and DIM was classified as month of lactation (1 to 10). Interactions between the covariates were never significant, and were not included. Least squares means of each lying variable were back-transformed where applicable and reported with $95 \%$ confidence intervals.

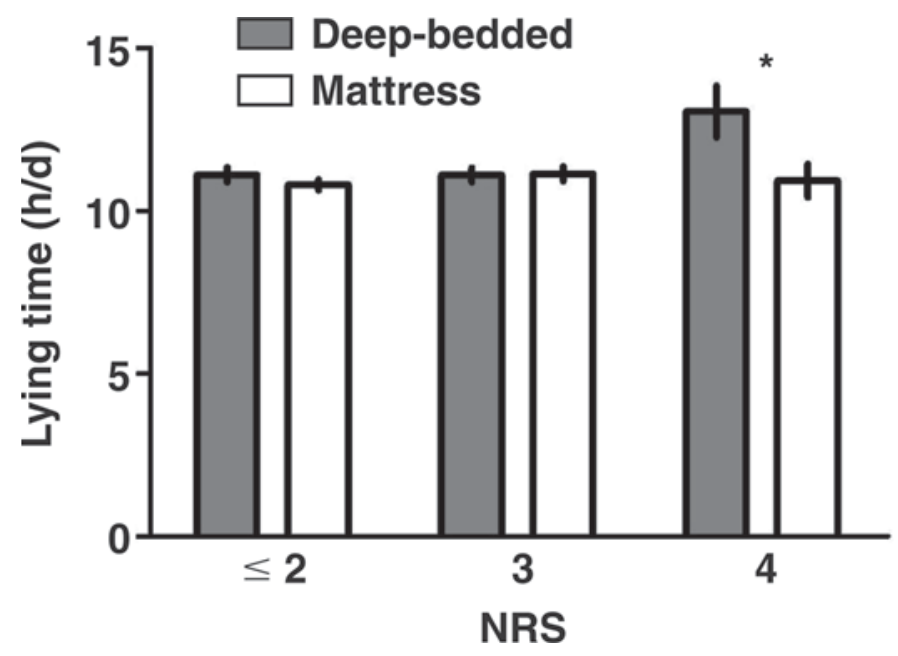

Figure 2. Mean lying time (h/d) of cows with Numerical Rating Score $(\mathrm{NRS}) \leq 2$, NRS $=3$, and NRS $=4$ on 11 farms using deepbedded stalls and 17 farms using mattress stalls. ${ }^{*}$ Significant difference at $P<0.05$.
Lying variables that showed significant association with lameness in the mixed models were used in receiver operating characteristic analysis, and threshold values were identified as those that had the highest combination of sensitivity and specificity. Odds ratios for LAME and SEVLAME were estimated using logistic regression (GLIMMIX; dist $=$ binomial and link $=$ logit) controlling for the random effect of farm. Parity was included in the logistic models as a covariate because it consistently showed a significant effect on lameness. Sensitivity and specificity of each behavioral threshold to discriminate LAME and SEVLAME cows were calculated using the FREQ procedure.

\section{RESULTS}

\section{Effect of Stall Surface in Relation to Lameness and Lying Behavior}

Of the 1,319 cows gait scored, $943(71.5 \%)$ had NRS $\leq 2,280(21.2 \%)$ had NRS $=3$, and $96(7.3 \%)$ had NRS $=4$. The mean prevalence of SEVLAME $(\mathrm{NRS}=4)$ was $9.3 \pm 1.3 \%$ (mean $\pm \mathrm{SE}$ ) on MAT farms compared with $4.4 \pm 1.2 \%$ on DB farms (Figure $1 ; P=0.02$ ). The SEVLAME cows spent more time lying down on DB farms than on MAT farms $(13.1 \pm 0.8$ vs. $10.9 \pm 0.5$ $\mathrm{h} / \mathrm{d} ; P=0.03$; Figure 2$)$. The frequency of lying bouts $(\mathrm{n} / \mathrm{d})$, average bout duration (min/bout), and SD of bout duration (min/bout) were similar across lameness categories on both DB and MAT farms (Table 2).

\section{Lying Behavior in Relation to Lameness}

Lying time (h/d), average bout duration ( $\mathrm{min} /$ bout), and SD of bout duration (min/bout) differed between SEVLAME cows (1) and those that were not (0) on DB farms, but not on MAT farms (Table 2). On DB farms, SEVLAME cows lay down $1.6 \mathrm{~h}$ longer per day $(P<$ $0.001)$, had longer lying bouts $(P=0.001)$, and greater $\mathrm{SD}$ of bout duration $(P=0.03)$.

\section{Lying Behavior as Indicator of Lameness}

Receiver operating characteristic analysis identified behavioral thresholds for SEVLAME, within DB farms, as lying time $>14.5 \mathrm{~h} / \mathrm{d}$; $\log$ bout duration $>4.5$ $\log (\min ) /$ bout (back-transformed bout duration $>90$ $\mathrm{min} /$ bout $)$; and SD of $\log$ bout duration $>4.0 \log (\mathrm{min}) /$ bout (back-transformed SD of bout duration $>55 \mathrm{~min} /$ bout) (Table 3 ). These behavioral thresholds were all associated with increased odds of SEVLAME on these farms $(P<0.05)$. The thresholds provided low sensitivity but high specificity in discriminating SEVLAME cows from those that were not. 
Table 2. Least squares means (and 95\% CI) of lying time (h/d), bout frequency (n/d), bout duration (min/bout), and SD of bout duration (min/bout) for LAME [Numerical Rating Score (NRS) $\geq 3$ ] or SEVLAME (NRS = 4) cows compared with cows that are not, on 11 farms using deep-bedded stalls and 17 farms using mattress stalls ${ }^{1}$

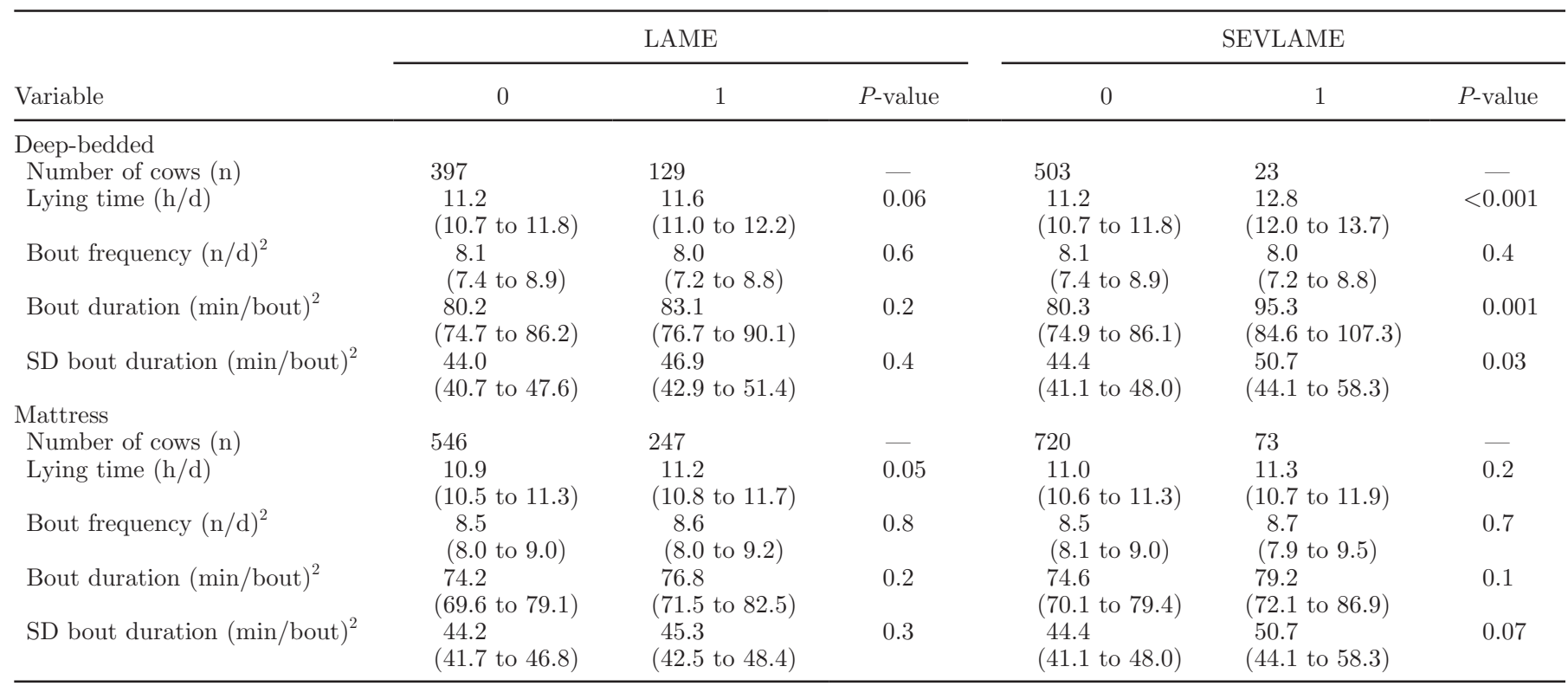

${ }^{1}$ Values are from mixed linear models accounting for fixed effects of parity and DIM, and a random effect of farm.

${ }^{2}$ Back-transformed least squares means (95\% CI) where natural log-transformation was applied to the variable.

\section{DISCUSSION}

Overall prevalence of LAME across the 28 farms was $28.5 \%$, including $7.3 \%$ of cows classified as SEVLAME. These values are similar to previously reported values of $24.6 \%$ among high-producing cows in 50 free-stall herds in Minnesota (Espejo et al., 2006), and 27.8\% during winter and $22.8 \%$ during summer among 15 freestall herds in Wisconsin (Cook, 2003). The prevalence was higher on MAT farms than on DB farms (33.0 vs. $22.9 \%$, respectively), again supporting previous findings (Cook, 2003; Cook et al., 2004; Espejo et al., 2006). In the present study, the effect of stall surface was driven by the difference in the prevalence of SEVLAME, suggesting that MAT stalls are a risk for more severe lameness in particular.

Understanding the behavioral differences between lame and nonlame cows may contribute to developing

Table 3. Numbers of cows that are SEVLAME [Numerical Rating Score (NRS) $=4 ; 1$ ] or not $(\mathrm{NRS}<4 ; 0)$ in each of the threshold categories, for 11 farms using deep-bedded stalls, odds ratios (OR) and 95\% CI for SEVLAME, sensitivity (Se) and specificity (Sp) of each threshold estimated by logistic regression including parity as a covariate and farm as a random effect

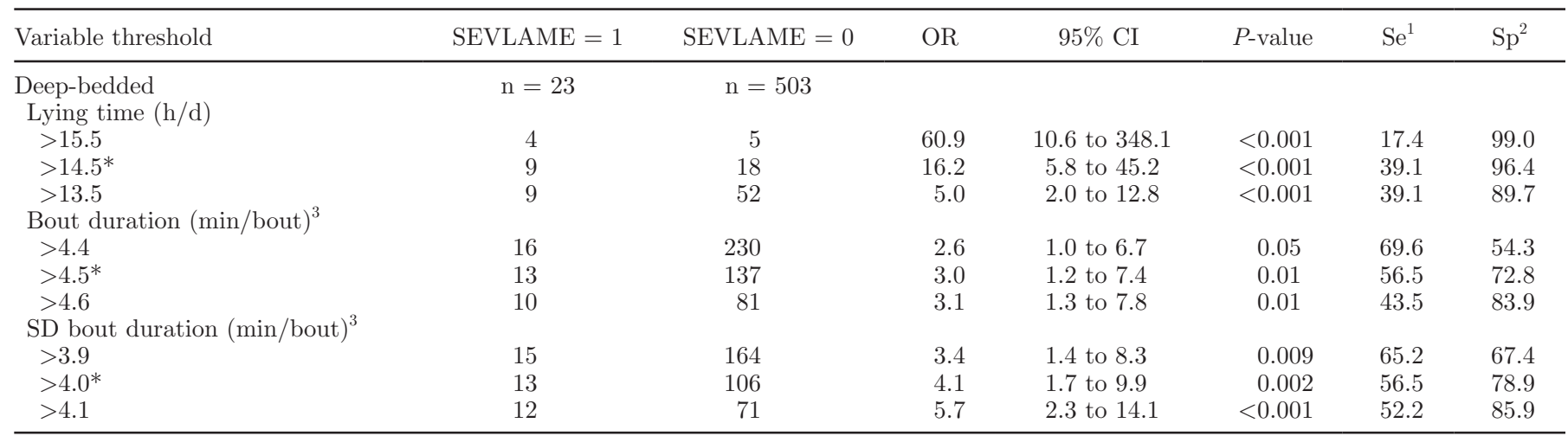

${ }^{1}$ Sensitivity $=$ the proportion of lame cows identified by the threshold of lying behavior.

${ }^{2}$ Specificity $=$ the proportion of nonlame cows correctly classified by the threshold of lying behavior.

${ }^{3}$ Natural log-transformed values.

*Threshold value with the highest average of sensitivity and specificity. 
practical tools for detecting lameness on-farm. An effect of stall surface on the behavior of lame cows has been reported; Cook et al. (2008) found that lame cows increased standing time in the stall by $3.3 \mathrm{~h} / \mathrm{d}$ on mattress stalls compared with stalls bedded with 5 to 8 $\mathrm{cm}$ of sand. In the current study, the SEVLAME cows increased lying time by $1.6 \mathrm{~h} / \mathrm{d}$ in DB stalls (comparable to sand stalls), but no difference was found for MAT stalls. Although the 2 studies measured different outcome variables (standing in the stall vs. total lying time), both showed that cow behavior was affected by stall surface and lameness.

Several studies have reported increased lying times by lame cows. Juarez et al. (2003) found that lame cows spent more time lying down; $25.2 \%$ of lame cows were lying down at the time of behavioral scans compared with $17.5 \%$ of sound cows. Similarly, Walker et al. (2008) found that lame cows spent $6.3 \%$ more time lying down during estrus compared with sound cows. Chapinal et al. (2009) reported that cows with sole ulcers spent $>1$ $\mathrm{h} / \mathrm{d}$ more lying down compared with cows without hoof lesions (13.8 vs. $12.6 \mathrm{~h} / \mathrm{d}$, respectively).

The particularly long lying times of SEVLAME cows on DB stalls suggests that these stalls provide a place where lame cows can lie down more comfortably. Increasing lying times may be more difficult on mattress stalls if these restrict the lying down and standing up movement (leading to the increased standing times reported by Cook et al., 2004, 2008). In general, when stalls are restrictive, limiting transitions from lying to standing and vice versa, cows spend more time standing in the stall instead of lying down (Tucker et al., 2004, 2005). These results highlight the importance of providing a comfortable lying place, especially for lame cows.

Within DB farms, SEVLAME cows had longer lying bouts compared with other cows. This finding supports Chapinal et al. (2009) who reported that cows with sole ulcers had longer bouts compared with cows with hemorrhages, dermatitis, or no lesions (93.3 vs. $82.7,81.1$, or $71.0 \mathrm{~min} /$ bout, respectively). Although the data showed that lame cows had longer bouts, the frequency of bouts was unchanged. This result is at least partly explained by increased variability (i.e., SD) in bout durations. Cook et al. (2004) found that the standing bout structure of lame cows was modified so that the proportion of short bouts was reduced and the proportion of long bouts was increased, especially for cows on mattress stalls. In the current study, the behavioral differences were evident only for DB stalls. Previous work has shown that mattresses reduced lying time, especially if managed with little or no bedding (Tucker et al., 2003; Tucker and Weary, 2004) as was the case for the MAT farms included in the current study. Reduced stall comfort, particularly for the lame cows, may contribute to the higher prevalence of SEVLAME on MAT farms.

Stall standing behavior has been identified as a key behavior that changes in response to lameness (Cook et al., 2004, 2008). Furthermore, increased time spent perching, with only 2 front feet inside the stall, was a risk factor for lameness (Galindo et al., 2000). Unfortunately, the data loggers used in this study could not discriminate between standing locations (inside or outside the stall) or positions (2 feet or 4 feet inside the stall). Development of technology that identifies standing position is desirable.

Lying behavior was not a sensitive diagnostic tool for lameness; clear thresholds to accurately identify lame cows were not established. This was because most cows, regardless of NRS, spent between 9 and $14 \mathrm{~h} / \mathrm{d}$ lying down. The thresholds did provide high specificity for correctly distinguishing cows that were not lame, suggesting that extreme lying behavior could be a useful element in a more sophisticated system for identifying lame cows. Our results indicated that cows with high lying times or long lying bouts were more likely lame and should be flagged for closer examination. It is likely that technology for automated measurement of lying behavior integrated with existing cow identification and activity monitoring systems will become commercially available in the near future. The present data may be applied to such systems as a component of lameness detection.

\section{CONCLUSIONS}

The prevalence of SEVLAME was higher on farms using MAT stalls compared with those using DB stalls. The SEVLAME cows housed on DB stalls spent more time lying down and had longer bouts compared with cows that were not SEVLAME, but there were no behavioral differences among cows with different degrees of lameness housed on MAT stalls. Lying behavior, especially high lying times ( $>14.5 \mathrm{~h} / \mathrm{d})$ and long lying bouts (>90 min/bout), was associated with increased odds of SEVLAME. Measures of lying behavior were not sensitive diagnostics for lameness. Automated measurement of lying behavior may be helpful as an element in a multi-pronged approach to lameness detection.

\section{ACKNOWLEDGMENTS}

We thank the producers and their staff for participating in this project. We are grateful to Alejandra Barrientos (UBC) for her technical help throughout the data collection period. We also thank Jason Lombard from the USDA who granted us permission to use 
components of the NAHMS (2007) cow comfort survey. $\mathrm{K}$. Ito was supported by scholarships provided by the Natural Sciences and Engineering Research Council of Canada (NSERC; Ottawa, ON, Canada) and Unifeed (Chilliwack, BC, Canada). This project was funded by the Westgen Endowment Fund (Milner, BC, Canada), Investment Agriculture Foundation of BC (Victoria, BC, Canada), Artex Barn Solutions Ltd. (Abbotsford, BC, Canada), Clearbrook Grain and Milling Co. Ltd. (Abbotsford, BC, Canada), Nutritech Solutions Ltd. (Abbotsford, BC, Canada), RitchieSmith Feeds Inc. (Abbotsford, BC, Canada), and Unifeed. The UBC Animal Welfare Program is funded through NSERC Industrial Research Chair program, with matching contributions from the Dairy Farmers of Canada, and many other donors listed on our website at: http://www.landfood.ubc.ca/animalwelfare.

\section{REFERENCES}

Barker, Z. E., J. R. Amory, J. L. Wright, R. W. Blowey, and L. E. Green. 2007. Management factors associated with impaired locomotion in dairy cows in England and Wales. J. Dairy Sci. 90:3270-3277.

Bicalho, R. C., S. H. Cheong, G. Cramer, and C. L. Guard. 2007a. Association between a visual and an automated locomotion score in lactating Holstein cows. J. Dairy Sci. 90:3294-3300.

Bicalho, R. C., V. S. Machado, and L. S. Caixeta. 2009. Lameness in dairy cattle: A debilitating disease or a disease of debilitated cattle? A cross-sectional study of lameness prevalence and thickness of the digital cushion. J. Dairy Sci. 92:3175-3184.

Bicalho, R. C., F. Vokey, H. N. Erb, and C. L. Guard. 2007b. Visual locomotion scoring in the first seventy days in milk: Impact on pregnancy and survival. J. Dairy Sci. 90:4586-4591.

Bicalho, R. C., L. D. Warnick, and C. L. Guard. 2008. Strategies to analyze milk losses caused by diseases with potential incidence throughout the lactation: A lameness example. J. Dairy Sci. 91:2653-2661.

Chapinal, N., A. M. de Passille, D. M. Weary, M. A. G. von Keyserlingk, and J. Rushen. 2009. Using gait score, walking speed, and lying behavior to detect hoof lesions in dairy cows. J. Dairy Sci. 92:4365-4374.

Cook, N. B. 2003. Prevalence of lameness among dairy cattle in Wisconsin as a function of housing type and stall surface. J. Am. Vet. Med. Assoc. 223:1324-1328.

Cook, N. B., T. B. Bennett, and K. V. Nordlund. 2004. Effect of free stall surface on daily activity patterns in dairy cows with relevance to lameness prevalence. J. Dairy Sci. 87:2912-2922.

Cook, N. B., M. J. Marin, R. L. Mentink, T. B. Bennett, and M. J. Schaefer. 2008. Comfort zone-design free stalls: Do they influence the stall use behavior of lame cows? J. Dairy Sci. 91:4673-4678.

Cook, N. B., R. L. Mentink, T. B. Bennett, and K. Burgi. 2007. The effects of heat stress and lameness on time budgets of lactating dairy cows. J. Dairy Sci. 90:1674-1682.

Cook, N. B., and K. V. Nordlund. 2009. The influence of the environment on dairy cow behavior, claw health and herd lameness dynamics. Vet. J. 179:360-369.

Cramer, G., K. D. Lissemore, C. L. Guard, K. E. Leslie, and D. F. Kelton. 2008. Herd- and cow-level prevalence of foot lesions in Ontario dairy cattle. J. Dairy Sci. 91:3888-3895.

Dippel, S., M. Dolezal, C. Brenninkmeyer, J. Brinkmann, S. March, U. Knierim, and C. Winckler. 2009. Risk factors for lameness in freestall-housed dairy cows across two breeds, farming systems, and countries. J. Dairy Sci. 92:5476-5486.

Endres, M. I., and A. E. Barberg. 2007. Behavior of dairy cows in an alternative bedded-pack housing system. J. Dairy Sci. 90:41924200.

Espejo, L. A., and M. I. Endres. 2007. Herd-level risk factors for lameness in high-producing Holstein cows housed in freestall barns. J. Dairy Sci. 90:306-314.

Espejo, L. A., M. I. Endres, and J. A. Salfer. 2006. Prevalence of lameness in high-producing Holstein cows housed in freestall barns in Minnesota. J. Dairy Sci. 89:3052-3058.

Flower, F. C., and D. M. Weary. 2006. Effect of hoof pathologies on subjective assessments of dairy cow gait. J. Dairy Sci. 89:139 146.

Galindo, F., and D. M. Broom. 2000. The relationships between social behavior of dairy cows and the occurrence of lameness in three herds. Res. Vet. Sci. 69:75-79.

Galindo, F., and D. M. Broom. 2002. The effects of lameness on social and individual behavior of dairy cows. J. Appl. Anim. Welf. Sci. 5:193-201.

Galindo, F., D. M. Broom, and P. G. G. Jackson. 2000. A note on possible link between behavior and the occurrence of lameness in dairy cows. Appl. Anim. Behav. Sci. 67:335-341.

Garbarino, E. J., J. A. Hernandez, J. K. Shearer, C. A. Risco, and W. W. Thatcher. 2004. Effect of lameness on ovarian activity in postpartum Holstein cows. J. Dairy Sci. 87:4123-4131.

González, L. A., B. J. Tolkamp, M. P. Coffey, A. Ferret, and I. Kyriazakis. 2008. Changes in feeding behavior as possible indicators for the automatic monitoring of health disorders in dairy cows. J. Dairy Sci. 91:1017-1028.

Green, L. E., V. J. Hedges, Y. H. Schukken, R. W. Blowey, and A. J. Packington. 2002. The impact of clinical lameness on the milk yield of dairy cows. J. Dairy Sci. 85:2250-2256.

Haskell, M. J., L. J. Rennie, V. A. Bowell, M. J. Bell, and A. B. Lawrence. 2006. Housing system, milk production, and zerograzing effects on lameness and leg injury in dairy cows. J. Dairy Sci. 89:4259-4266.

Hoedemaker, M., D. Prange, and Y. Gundelach. 2009. Body condition change ante- and postpartum, health and reproductive performance in German Holstein cows. Reprod. Domest. Anim. 44:167-173.

Ito, K., D. M. Weary, and M. A. G. von Keyserlingk. 2009. Lying behavior: Assessing within- and between-herd variation in freestall-housed dairy cows. J. Dairy Sci. 92:4412-4420.

Juarez, S. T., P. H. Robinson, E. J. DePeters, and E. O. Price. 2003. Impact of lameness on behavior and productivity of lactating Holstein cows. Appl. Anim. Behav. Sci. 83:1-14.

Leonard, F. C., J. M. O'Connell, and K. J. O'Ferrell. 1996. Effects of overcrowding on claw health in first-calved Friesian heifers. Br. Vet. J. 152:459-472.

O'Callaghan, K. A., P. J. Cripps, D. Y. Downham, and R. D. Murray. 2003. Subjective and objective assessment of pain and discomfort due to lameness in dairy cattle. Anim. Welf. 12:605-610.

Philipot, J. M., P. Pluvinage, I. Cimarosti, P. Sulpice, and F. Bugnard. 1994. Risk-factors of dairy-cow lameness associated with housing conditions. Vet. Res. 25:244-248.

SAS Institute. 2004. SAS 9.1 User's Guide. SAS Institute Inc., Cary, NC.

SAS Institute. 2008. SAS/STAT 9.1 User's Guide: The Glimmix Procedure. SAS Institute Inc., Cary, NC.

Singh, S. S., W. R. Ward, K. Lautenbach, and R. D. Murray. 1993. Behavior of lame and normal dairy-cows in cubicles and in a straw yard. Vet. Rec. 133:204-208.

Tucker, C. B., and D. M. Weary. 2004. Bedding on geotextile mattresses: How much is needed to improve cow comfort? J. Dairy Sci. 87:2889-2895.

Tucker, C. B., D. M. Weary, and D. Fraser. 2003. Effects of three types of free-stall surfaces on preferences and stall usage by dairy cows. J. Dairy Sci. 86:521-529. 
Tucker, C. B., D. M. Weary, and D. Fraser. 2004. Free-stall dimensions: Effects on preference and stall usage. J. Dairy Sci. 87:12081216.

Tucker, C. B., D. M. Weary, and D. Fraser. 2005. Influence of neck-rail placement on free-stall preference, use, and cleanliness. J. Dairy Sci. 88:2730-2737.

Walker, S. L., R. F. Smith, J. E. Routly, D. N. Jones, M. J. Morris, and H. Dobson. 2008. Lameness, activity time-budgets, and estrus expression in dairy cattle. J. Dairy Sci. 91:4552-4559.
Warnick, L. D., D. Janssen, C. L. Guard, and Y. T. Grohn. 2001. The effect of lameness on milk production in dairy cows. J. Dairy Sci. 84:1988-1997.

Whay, H. R., D. C. J. Main, L. E. Green, and A. J. F. Webster 2003. Assessment of the welfare of dairy cattle using animal-based measurements: Direct observations and investigation of farm records. Vet. Rec. 153:197-202. 